Supporting information for:

\title{
Photocatalytic Transfer Hydrogenation in Water: Insight into Mechanism and Catalyst Speciation
}

David M. Kaphan, ${ }^{a, *}$ Kelsey R. Brereton, ${ }^{b}$ Rachel C. Klet, ${ }^{a}$ Ryan J. Witzke, ${ }^{a}$ Alexander J. M. Miller, ${ }^{c, *}$ Karen L. Mulfort, ${ }^{a}$ Massimiliano Delferro, ${ }^{a}$ David M. Tiede ${ }^{a, *}$

${ }^{a}$ Chemical Sciences and Engineering Division, Argonne National Laboratory, Lemont, Illinois 60439, United States

${ }^{b}$ Department of Chemistry, Pepperdine University, Malibu, CA 90263, United States

${ }^{C}$ Department of Chemistry, University of North Carolina at Chapel Hill, Chapel Hill, North Carolina 27599, United States 


\section{Table of Contents}

$\begin{array}{ll}\text { General methods } & \text { S3 }\end{array}$

$\begin{array}{ll}\text { Instrumentation and sample preparation } & \mathbf{S 3}\end{array}$

$\begin{array}{ll}\text { Representative catalytic reaction procedures } & \text { S4 }\end{array}$

Supplemental Figures

- Photographs of experimental setups $\quad$ S5

- Representative kinetic profile $\quad$ S6

- Initial control reactions $\quad$ S6

- Ex situ and operando time resolved ${ }^{1} \mathrm{H}$ NMR Spectra $\quad$ S9

- Supplemental figures for the determination of reactant orders $\quad$ S11

- Effect of delayed ketone addition $\quad$ S13

- Kinetic profiles with 1-tBu and 1-OMe $\quad$ S14

- Control experiments with $\left[\mathrm{Cp}^{*} \operatorname{Ir}\left(\mathrm{OH}_{2}\right)_{3}\right]\left[\mathrm{SO}_{3} \mathrm{CF}_{3}\right]_{2} \quad$ S16

- $\quad$ ESI-MS analysis of reaction mixture $\quad$ S18

$\begin{array}{ll}\text { References } & \text { S21 }\end{array}$ 


\section{$\underline{\text { General Methods }}$}

Air- and moisture-sensitive synthetic procedures were conducted using standard Schlenk line techniques or in a glovebox under nitrogen atmosphere. Photochemical iridium catalyzed ketone reduction reactions were set up under flowing $\mathrm{N}_{2}$ from a Schlenk line for preliminary reactivity studies and in a $\mathrm{N}_{2}$ filled glovebox dedicated to air sensitive aqueous chemistry for the kinetic studies. $\mathrm{D}_{2} \mathrm{O}$ was purchased from Sigma-Aldrich and degassed by sparging with $\mathrm{N}_{2}$ for 45 minutes before use or storage in the glovebox. $[\mathrm{Cp} * \operatorname{Ir}(\mathrm{bpy})(\mathrm{Cl})][\mathrm{Cl}],{ }^{1}[\mathrm{Cp} * \operatorname{Ir}(\mathrm{bpy}-\mathrm{OMe})(\mathrm{Cl})][\mathrm{Cl}],{ }^{2}$ $[\mathrm{Cp} * \operatorname{Ir}(\mathrm{bpy}-\mathrm{OMe})(\mathrm{Cl})][\mathrm{Cl}],{ }^{3} \quad\left[\mathrm{Cp} * \operatorname{Ir}(\mathrm{Cl})_{2}\right]_{2},{ }^{4} \quad\left[\mathrm{Cp} * \operatorname{Ir}\left(\mathrm{OH}_{2}\right)_{3}\right]\left[\mathrm{SO}_{3} \mathrm{CF}_{3}\right]_{2},{ }^{5}$ $\left[\mathrm{Cp} * \operatorname{Ir}(\mathrm{bpy})\left(\mathrm{OH}_{2}\right)\right]\left[\mathrm{SO}_{3} \mathrm{CF}_{3}\right]_{2}{ }^{6}$ were prepared according to previously reported literature procedures.

\section{Instrumentation}

Solution-phase Nuclear Magnetic Resonance (NMR) spectra were collected using a Bruker UltraShield $500 \mathrm{MHz}$ spectrometer $\left({ }^{1} \mathrm{H} \mathrm{NMR}=500 \mathrm{MHz}\right)$ and were referenced to residual solvent signals. Spectra were then processed using Mnova by Mestrelab Research. Phase correction was applied followed by baseline correction (Whittaker smoother) and both were performed prior to integration of peaks. (Note: solvent suppression resulted in integration errors, therefore the effect of the large solvent peak for $\mathrm{D}_{2} \mathrm{O} / \mathrm{H}_{2} \mathrm{O}$ NMR spectra was removed with the Whittaker smoother function. This must be done with care avoid overfitting the baseline and introducing error.)

Both initial screening of catalytic reactivity and irradiation of J. Young NMR tube reactions were performed on an orbital shaker (100 rpm) with LED light sources embedded in an eight well aluminum block. For NMR scale reactions, agitation of the reaction mixture assisted with dislodging $\mathrm{H}_{2}$ bubbles. LEDs were obtained from ThorLabs, model number M455D1 (455 nm). The power supply was GW Instek model number GPS-2303, and was set to $0.1 \mathrm{~A}, 0.023 \mathrm{~V}$. For J. Young NMR tube reactions the LED block was placed on its side and stainless steel tubes were affixed to the body of the block to ensure consistent placement of the NMR tubes (Figure S1) Operando reaction monitoring was performed by fiberoptic illumination of the reaction mixture while inside the NMR spectrometer (Figure S2). ${ }^{7}$ The LED was power by a Thorlab DC2100 power source and experiments were performed at full light power. The light was focused on one end of the fiber optic cable with a Thorlab aspheric condenser lens. Protective films were removed from the last $4 \mathrm{~cm}$ of the opposite end of the fiber optic cable and the surface was roughened with sandpaper to allow even illumination through the sides of the cable, which was inserted into a coaxial glass insert within the main NMR tube. ESI-MS were collected on a ThermoFisher LCQ Fleet from dilute aqueous solutions in positive ionization mode. 


\section{Representative conditions for preliminary catalytic screening}

A septum topped $20 \mathrm{~mL}$ vial was charged with a stock solution of cyclohexanone $(24.5 \mathrm{mg}, 0.25$ mmol, 1 equiv.), sodium formate ( $170.0 \mathrm{mg}, 2.5 \mathrm{mmol}, 10$ equiv.), and 2-butanol (18.5 mg, 0.25 mmol, 1 equiv.) as an internal standard in deionized $\mathrm{H}_{2} \mathrm{O}(5 \mathrm{~mL})$. To this solution was added [Cp* $\operatorname{Ir}(\mathrm{bpy}) \mathrm{Cl}][\mathrm{Cl}]\left(13.9 \mathrm{mg}, 0.025 \mathrm{mmol}, 0.1\right.$ equiv.) as a stock solution in deionized $\mathrm{H}_{2} \mathrm{O}(5$ $\mathrm{mL}$ ). The mixture was sparged for 30 minutes with nitrogen and then illuminated on the shaker table. $0.1 \mathrm{~mL}$ aliquots were collected periodically, diluted with $0.4 \mathrm{~mL}$ of $\mathrm{D}_{2} \mathrm{O}$ and analyzed by ${ }^{1} \mathrm{H}$ NMR spectroscopy.

\section{Representative conditions for kinetic monitoring in a J. Young NMR tube}

In a $\mathrm{N}_{2}$ glovebox (wet atmosphere) a $2 \mathrm{~mL}$ volumetric flask wrapped in aluminum foil was charged with sodium formate (68 mg, $1.0 \mathrm{mmol}, 10$ equiv), [Cp* Ir(bpy)Cl][Cl] $(2.77 \mathrm{mg}, 0.005 \mathrm{mmol}$, 0.05 equiv), cyclohexanone $(9.5 \mathrm{mg}, 0.10 \mathrm{mmol}, 1$ equiv), and sodium 3-trimethylsilylpropane-1sulfonate as internal standard ( $4.91 \mathrm{mg}, 0.03 \mathrm{mmol}, 0.3$ equiv). $0.1 \mathrm{~mL}$ of $\mathrm{D}_{2} \mathrm{O}$ was added, and the volumetric flask was then filled to the $2 \mathrm{~mL}$ mark with deionized $\mathrm{H}_{2} \mathrm{O} .0 .5 \mathrm{~mL}$ of the resulting solution was transferred to a J. Young NMR tube, which was wrapped in foil, sealed, and removed from the glovebox. An initial ${ }^{1} \mathrm{H}$ NMR spectrum was collected, followed by illumination on the shaker table in the orientation shown in Figure S1. The NMR tube was protected from ambient light with aluminum foil when not being actively irradiated. Kinetic profiles were generated based on ${ }^{1} \mathrm{H}$ NMR signals at $2.28 \mathrm{ppm}$ corresponding to the $\alpha$ protons of cyclohexanone, and the resonances from $0.90-1.22 \mathrm{ppm}$ corresponding to six protons of cyclohexanol. 


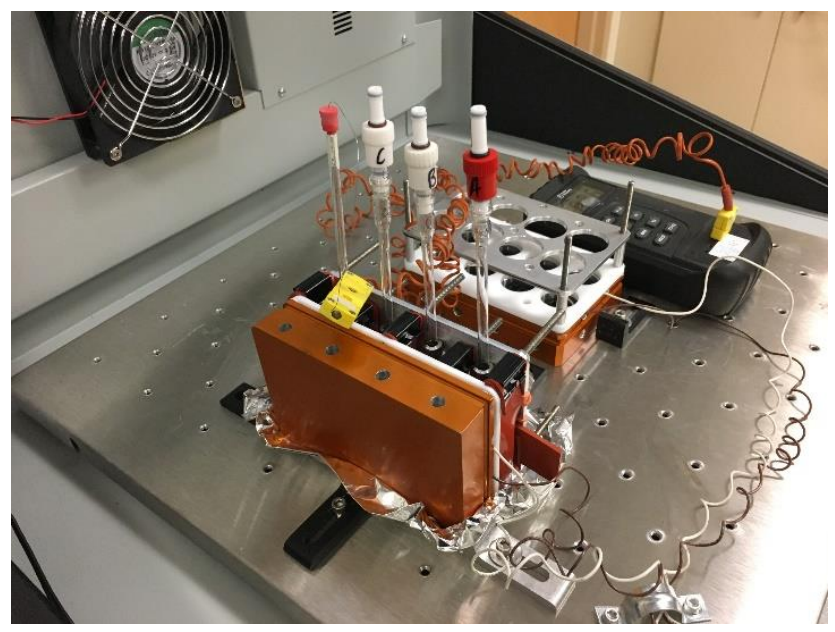

Figure S1. Photograph of parallel illumination setup for reactions in J. Young NMR tubes.

LED off:

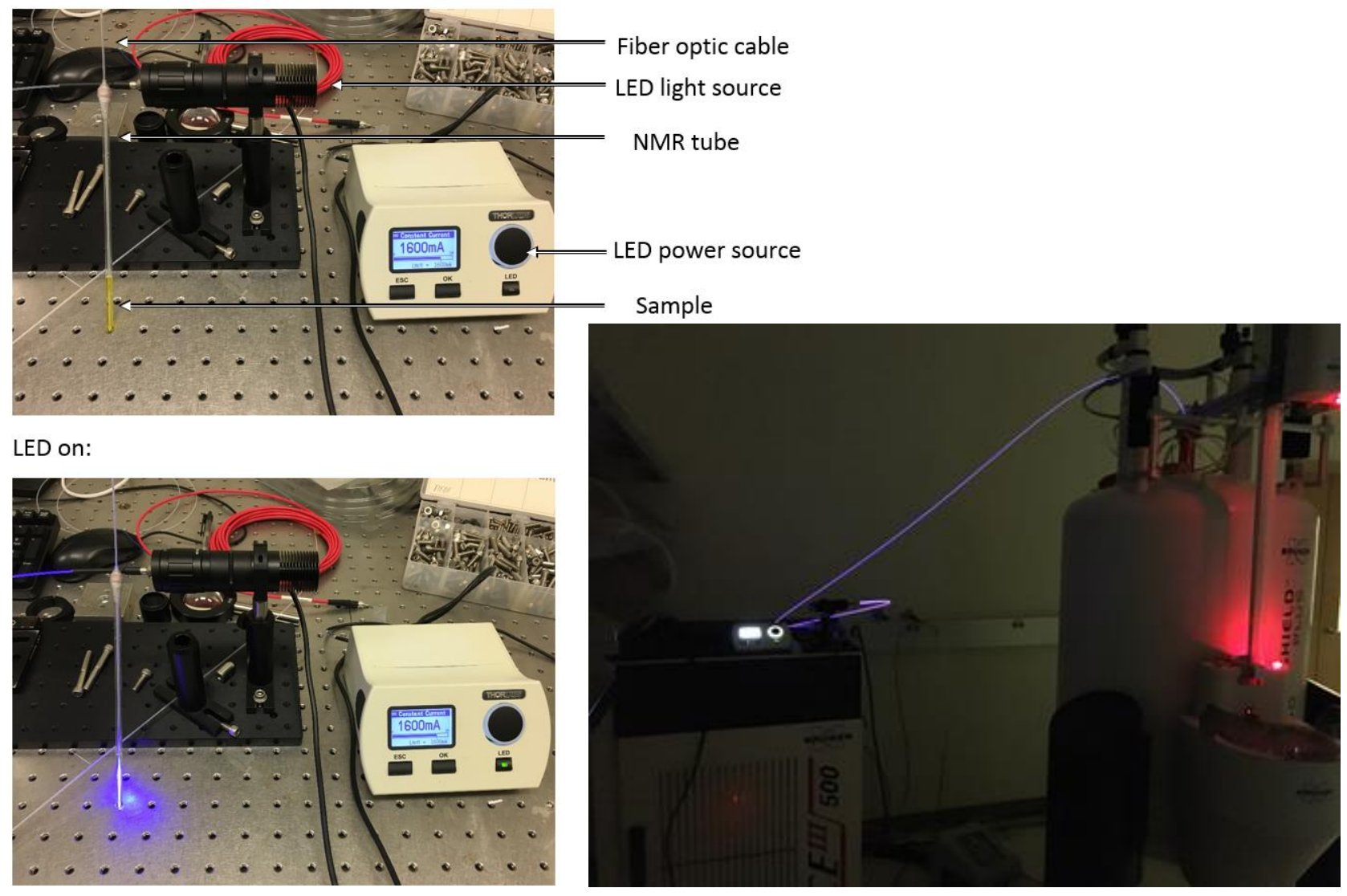

Figure S2. Apparatus for operando NMR reaction illumination. 


\section{Representative kinetic profile}
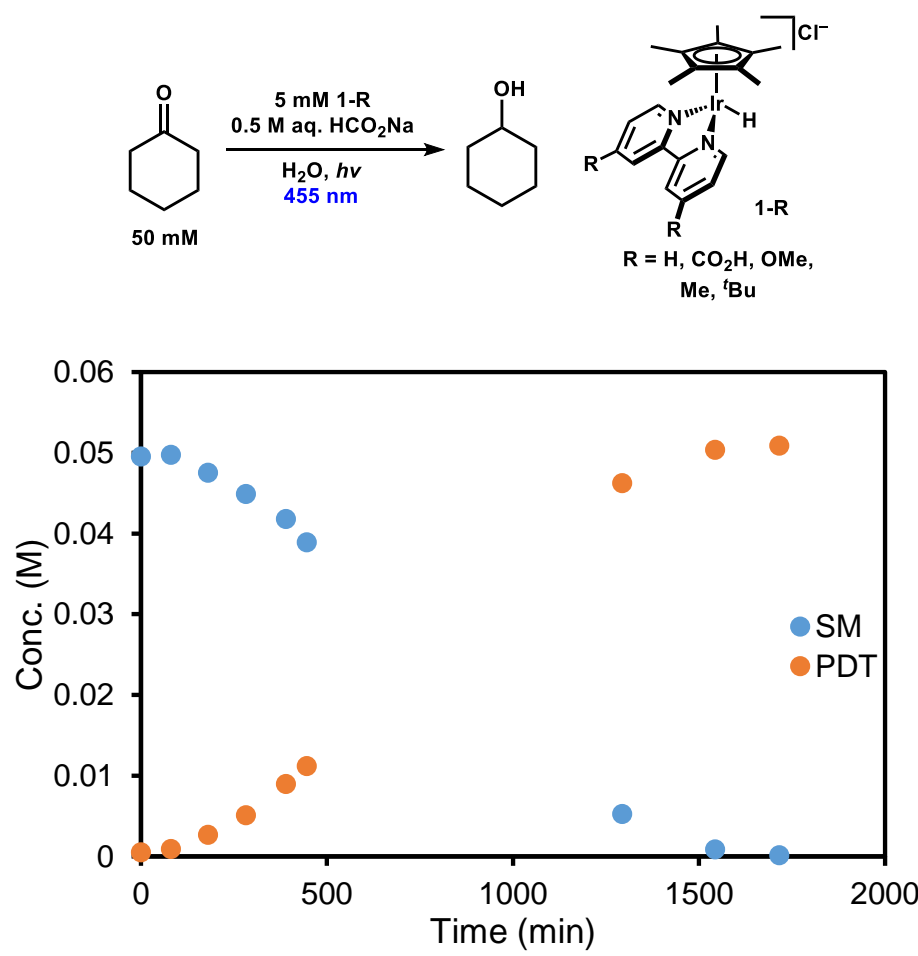

Figure S3. Kinetic profile for the reduction of cyclohexanone and appearance of cyclohexanol catalyzed by $\mathbf{1 - H}$.

\section{Control reactions}

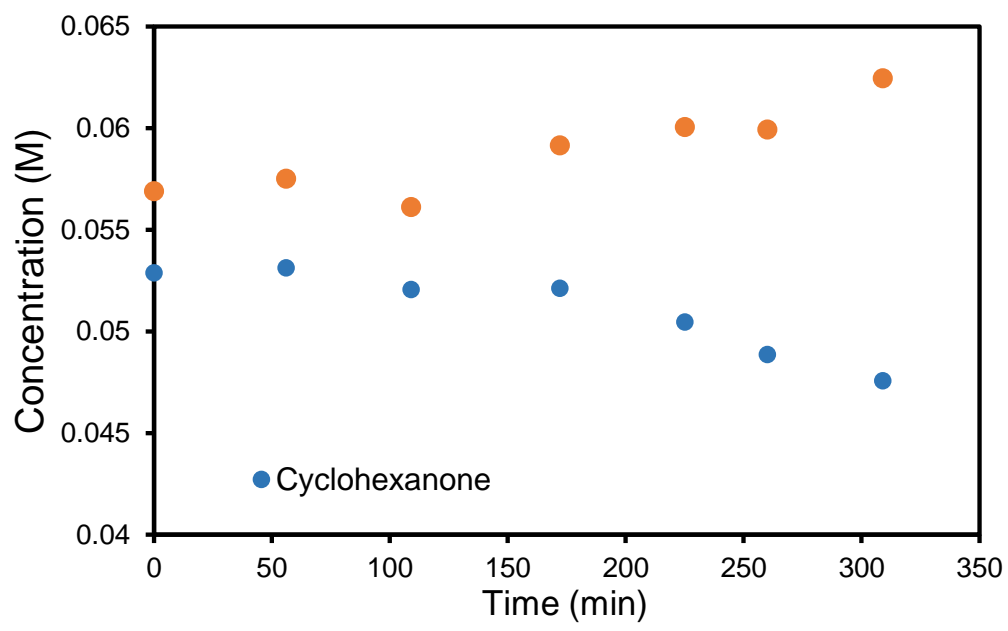

Figure S4. Effect of the addition of cyclohexanol at the beginning of reaction to establish that the induction period is not the result of product formation resulting in autocatalysis. 


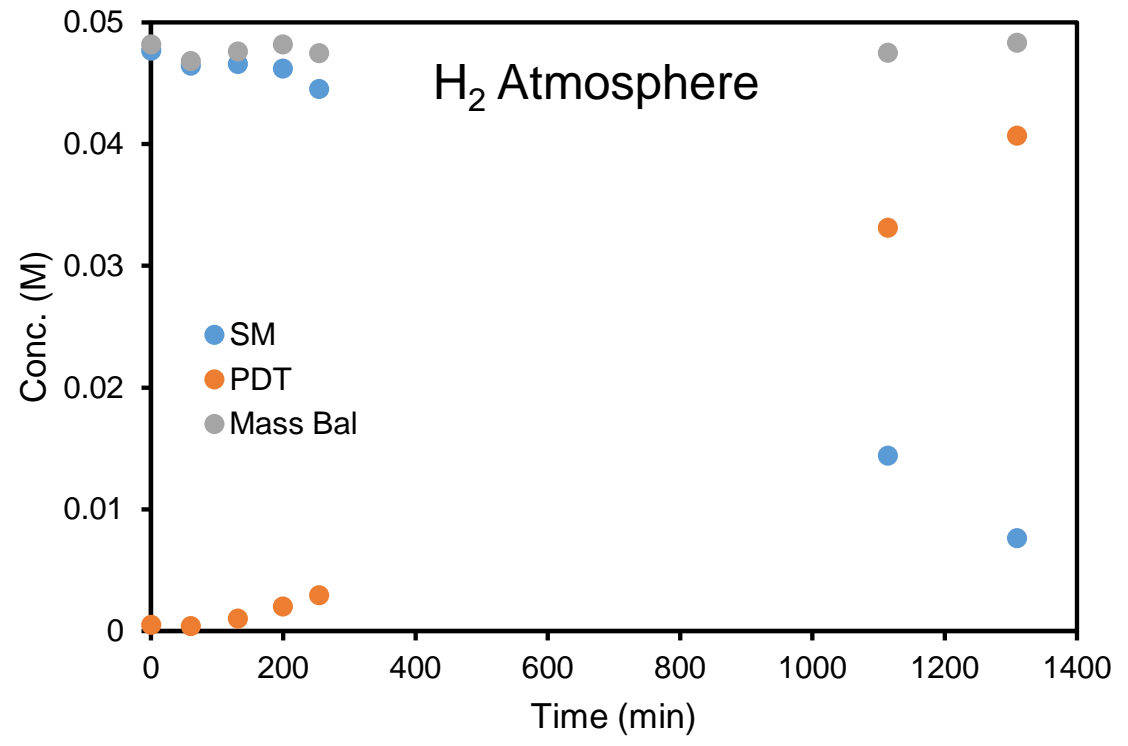

Figure S5. Kinetic profile for the cyclohexanone reduction catalyzed by $\mathbf{1 - H}$ under an atmosphere of $1 \mathrm{~atm} \mathrm{H}_{2}$, which does not influence the induction period. 

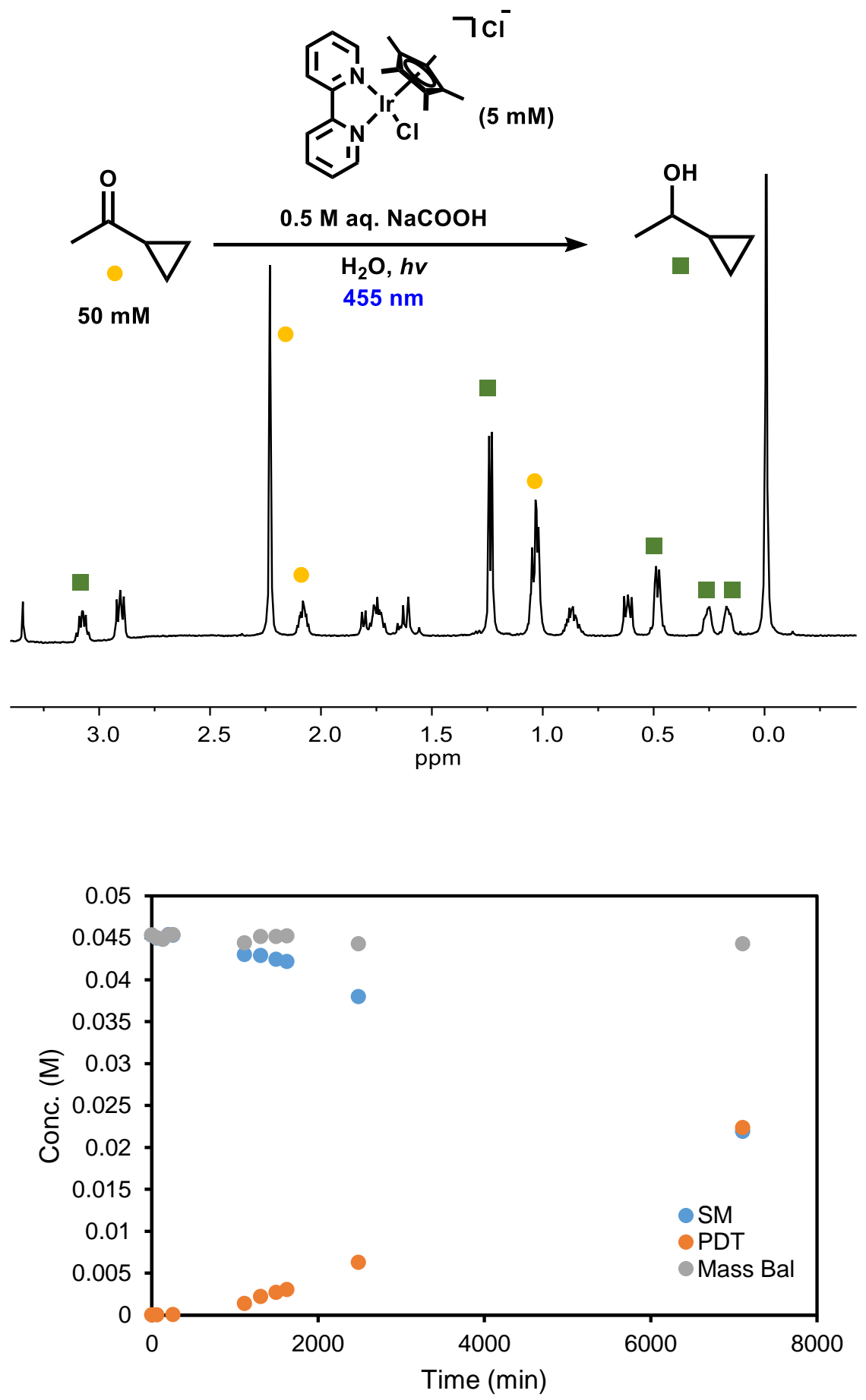

Figure S6. Photochemical reduction of methycyclopropylketone catalyzed by $\mathbf{1 - H}$. Representative ${ }^{1} \mathrm{H}$ NMR spectrum (top) and kinetic profile featuring an induction period (bottom). 


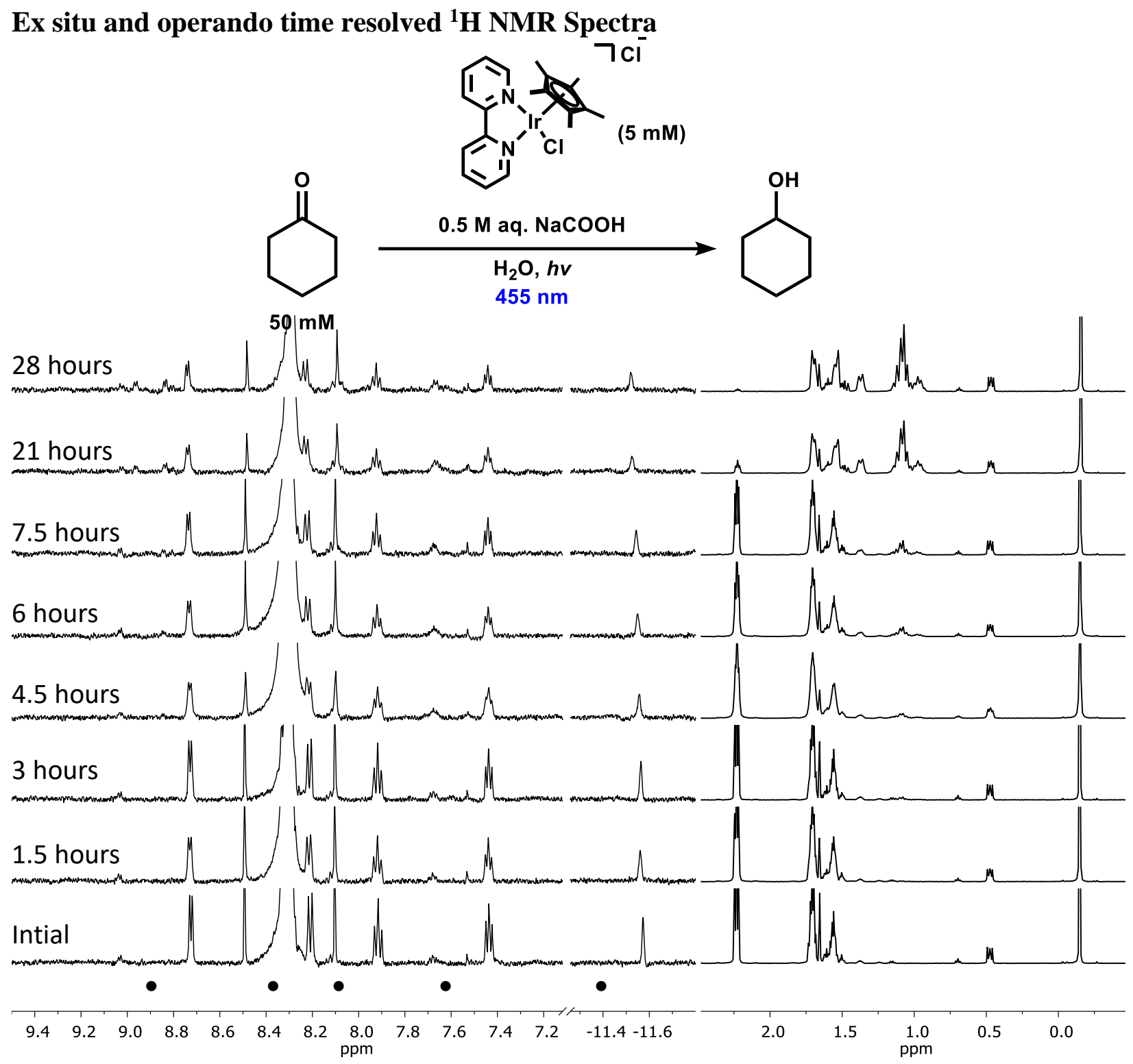

Figure S7. Extended stack of ex situ ${ }^{1} \mathrm{H}$ NMR spectrum of the 1-H catalyzed photoreduction of cyclohexanone. Catalyst resonances shown on the left and substrate / product resonances on the right. Resonances at $-11.6,7.4,7.9,8.2$, and $8.7 \mathrm{ppm}(\bullet)$ are associated with complex $\mathbf{1}-\mathbf{H}$. 

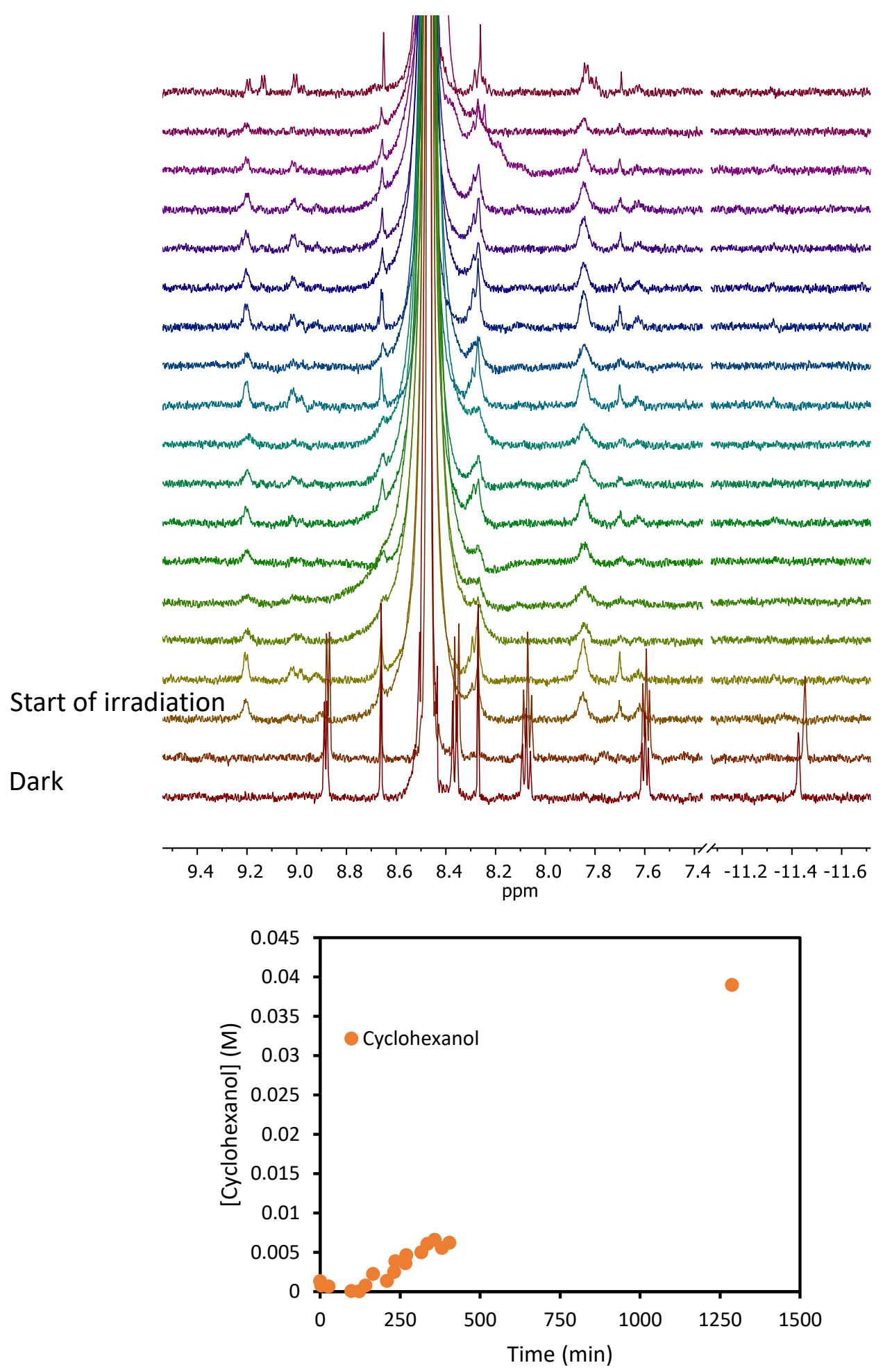

Figure S8. Operando ${ }^{1} \mathrm{H}$ NMR spectroscopy experiment on the 1-H catalyzed photoreduction of cyclohexanone with the setup depicted in Figure S2. ${ }^{1} \mathrm{H}$ NMR spectra (top) corresponding to datapoints in reaction profile (bottom) showing induction period. Line broadening is the result of $\mathrm{H}_{2}$ bubbles accumulating on the walls of the NMR tube, which had to be manually removed periodically by agitation of the NMR tube. 


\section{Supplemental figures for the determination of reactant orders}

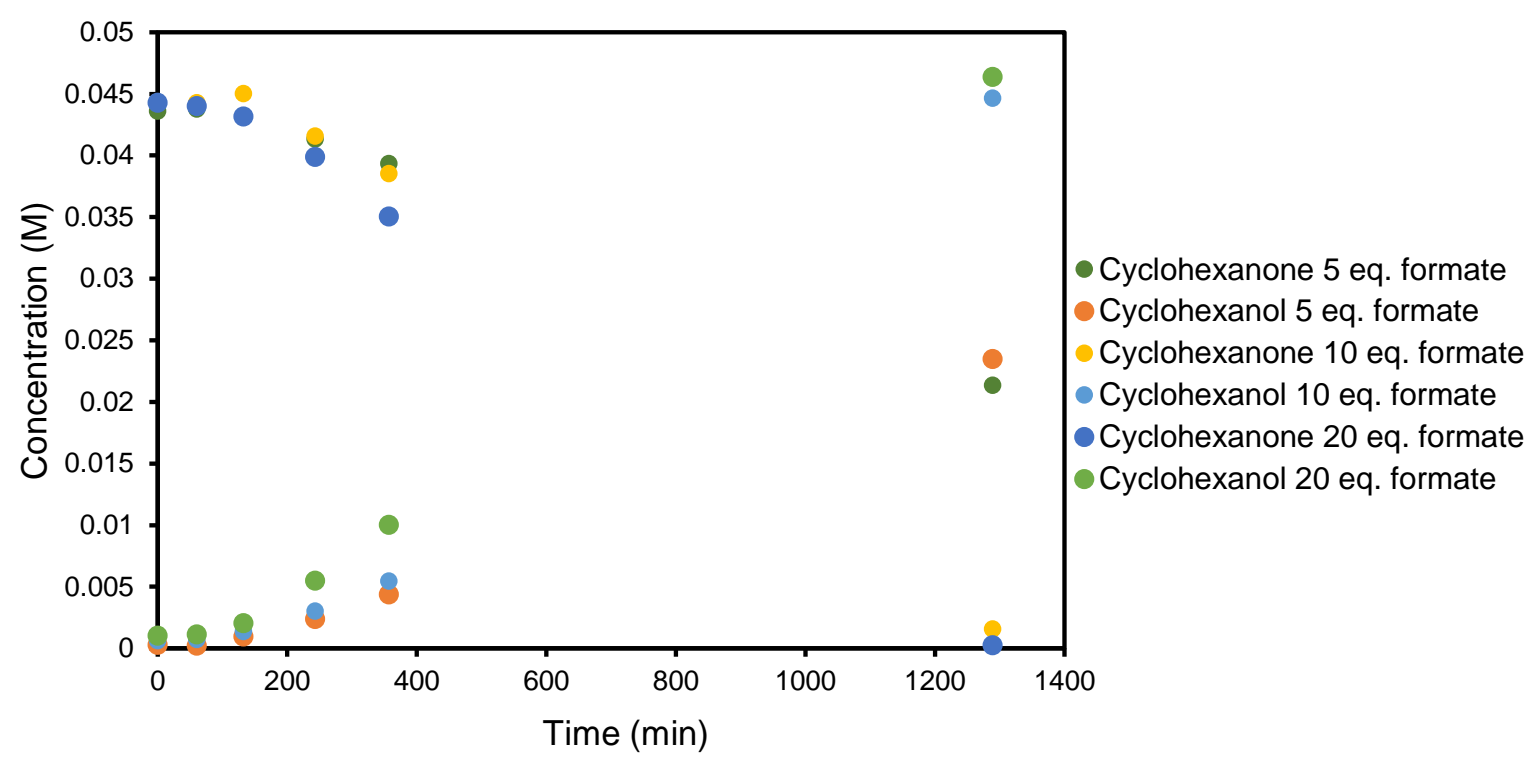

Figure S9. Effect of initial formate excess $(5,10,20$ equiv relative to cyclohexanone) on cyclohexanone reduction.

Formate comsumption double log plot

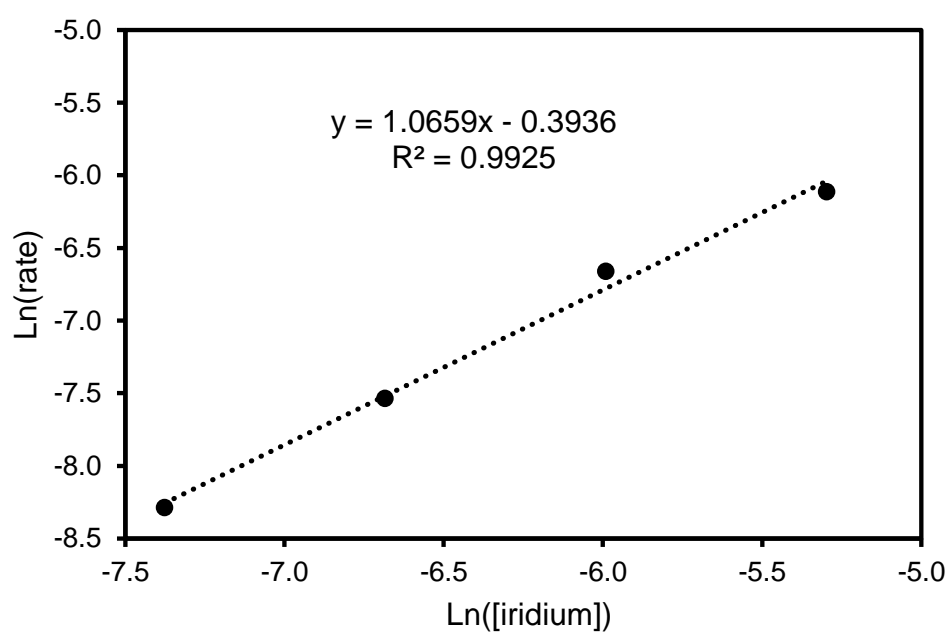

Figure S10. Double log plot of the rate of formate consumption as a function of the initial iridium concentration by initial rates. A slope within error of 1 indicates first order in the consumption of formate and by extension the evolution of hydrogen, which dominates the consumption of formate. 


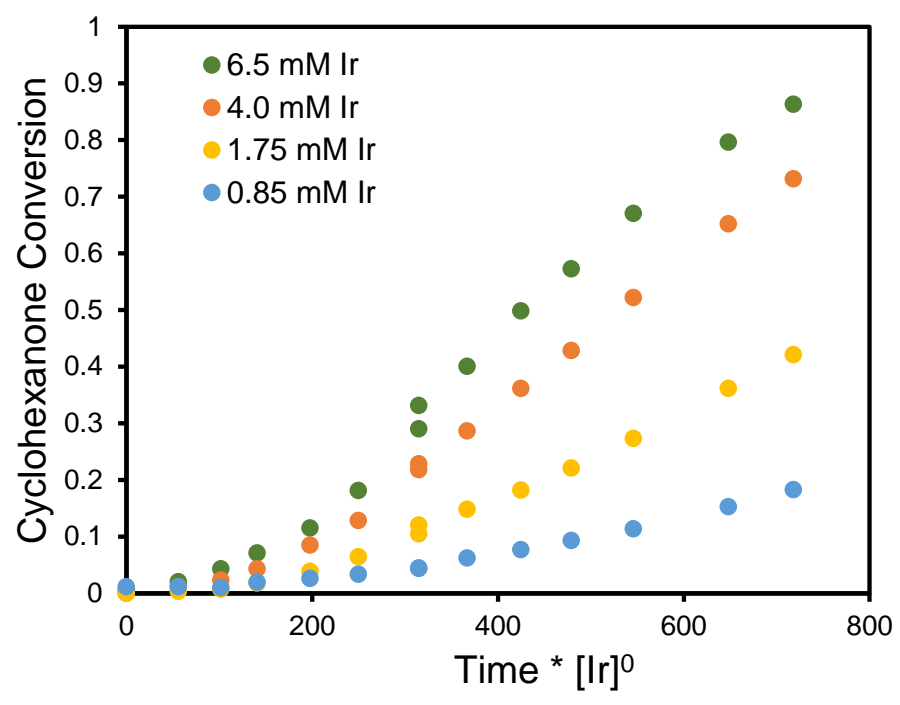

Figure S11. VTNA for the appearance of cyclohexanol with zero order in iridium (lack of overlap contradicts this order).

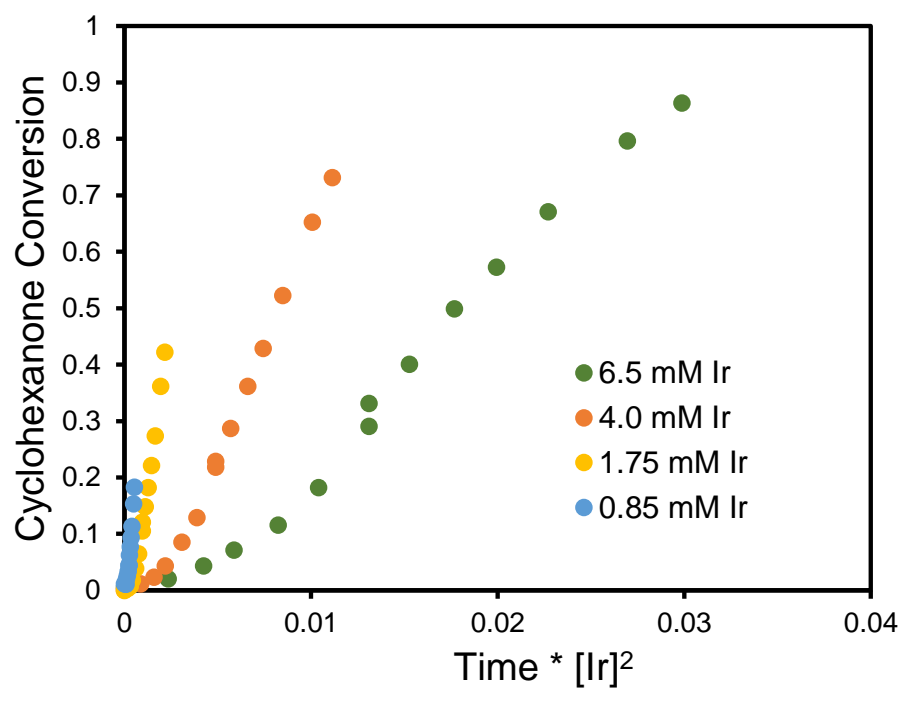

Figure S12. VTNA for the appearance of cyclohexanol with second order in iridium (lack of overlap contradicts this order). 


\section{Effect of delayed ketone addition}

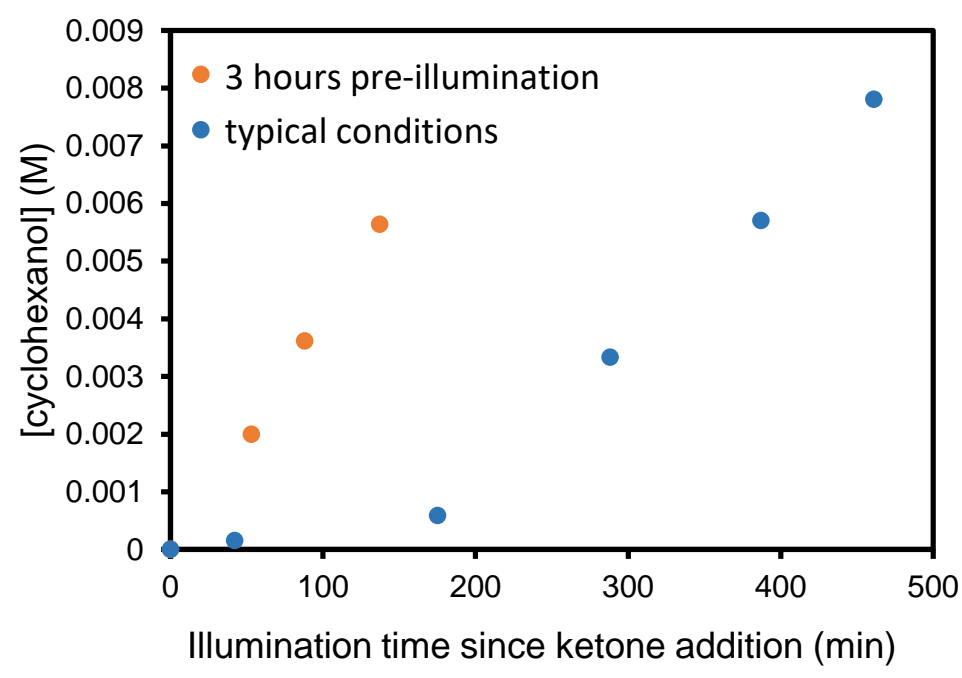

Figure S13. Overlay of the induction period observed under standard conditions (blue) with a profile displaying no induction period obtained by illumination the reaction mixture without the ketone substrate for three hours followed by the addition of the cyclohexanone. 
Kinetic profiles with 1-tBu and 1-OMe

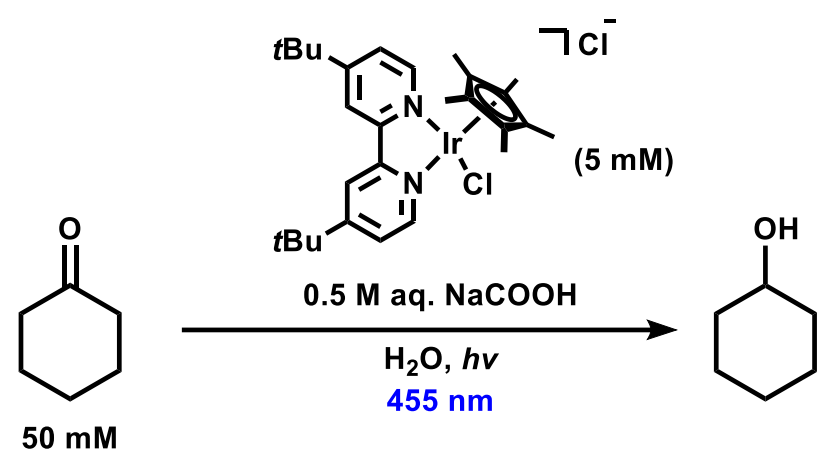

$\left[\mathrm{Cp}^{*} \operatorname{Ir}\left(4,4^{\prime}-(\mathrm{tBu})_{2}-\mathrm{bpy}\right) \mathrm{Cl}\right] \mathrm{Cl}$
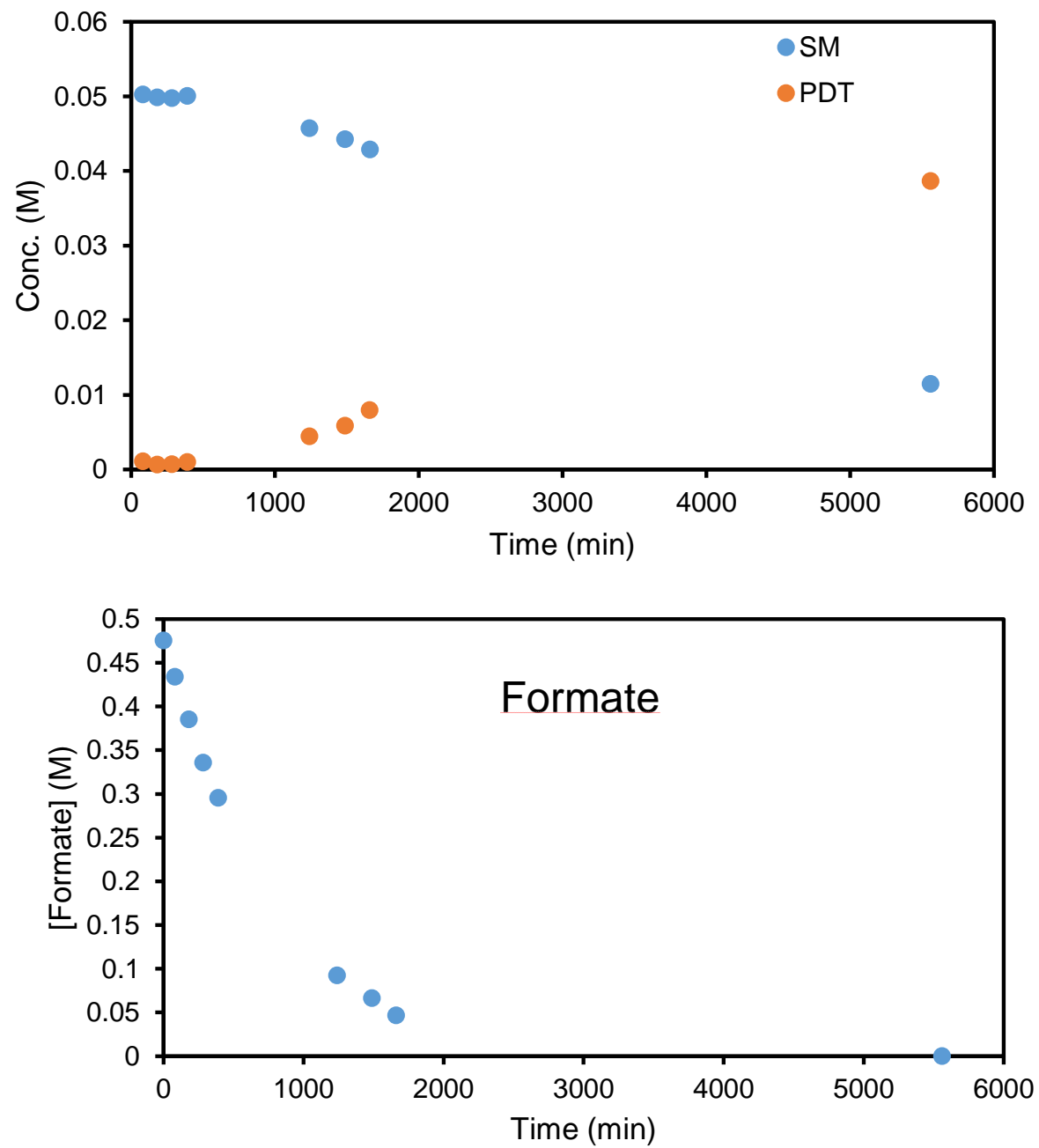

Figure S14. Photochemical reduction of cyclohexanone catalyzed by 1-tBu. (Top) kinetic profile of cyclohexanone (blue) consumption and cyclohexanol (orange) formation, (bottom) kinetic profile of formate consumption. 

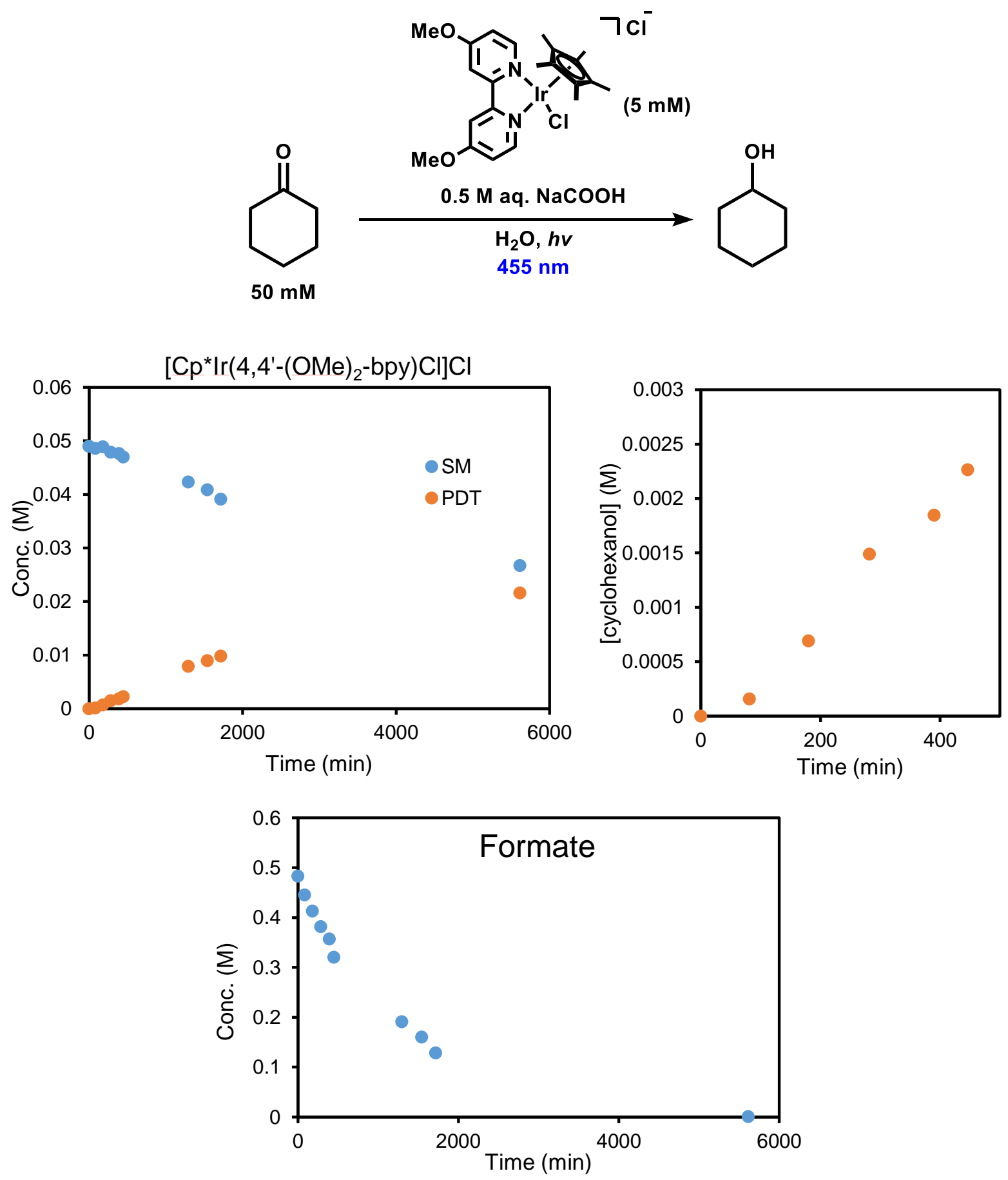

Figure S15. Photochemical reduction of cyclohexanone catalyzed by 1-OMe. (Top left) kinetic profile of cyclohexanone (blue) consumption and cyclohexanol (orange) formation, (top right) Enlarged region showing early conversion of cyclohexanone showing small but present induction period, and (bottom) kinetic profile of formate consumption. 


\section{Control experiments with $\left[\mathrm{Cp} * \operatorname{Ir}\left(\mathrm{OH}_{2}\right)_{3}\right]\left[\mathrm{SO}_{3} \mathrm{CF}_{3}\right]_{2}$}
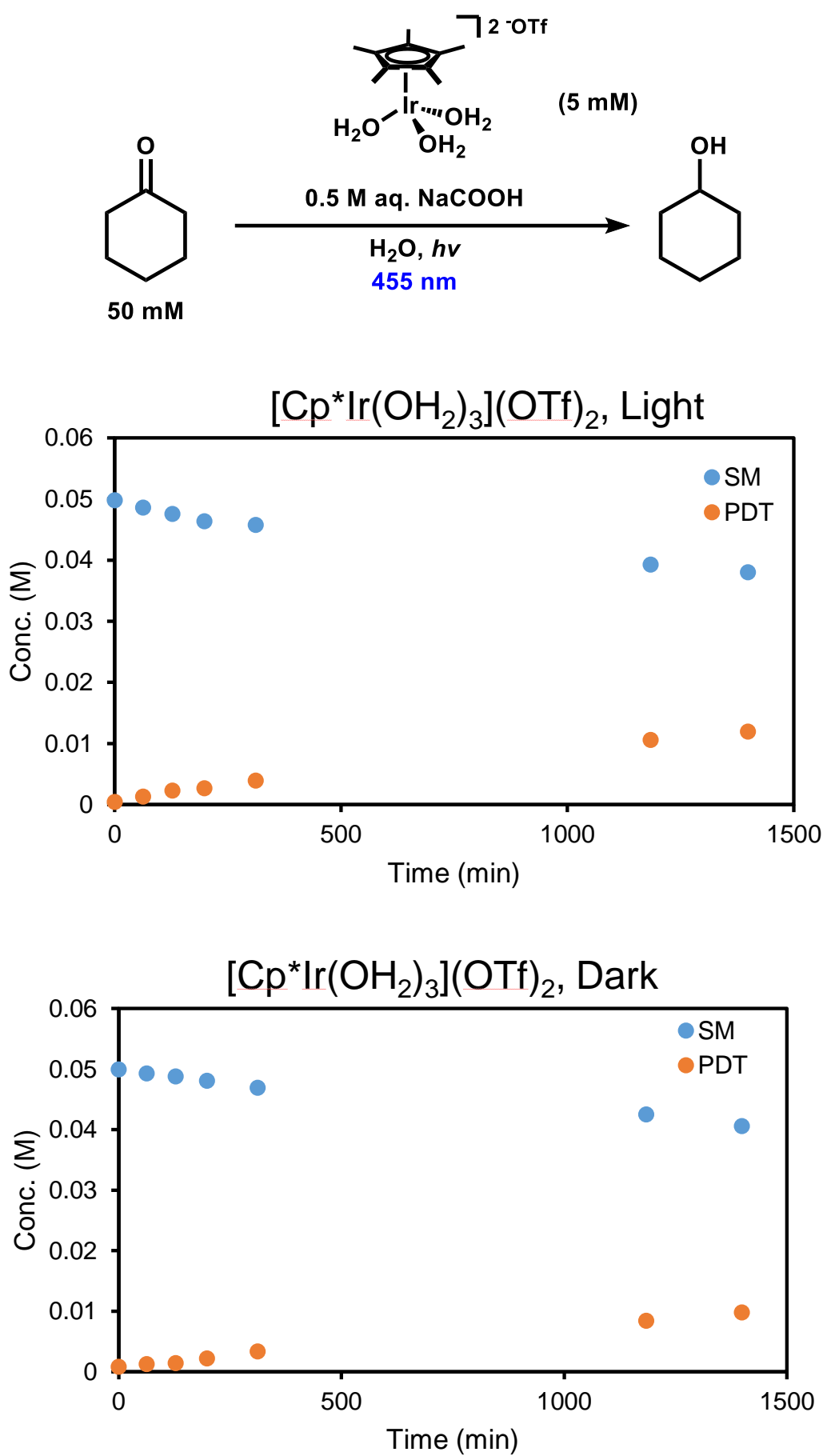

Figure S16. Control experiment with $\left[\mathrm{Cp} * \operatorname{Ir}\left(\mathrm{OH}_{2}\right)_{3}\right]\left[\mathrm{SO}_{3} \mathrm{CF}_{3}\right]_{2}$ instead of 1-H. No photoresponse is observed in the absence of the bipyridine ligand, however the dark reaction is faster for $\left[\mathrm{Cp}^{*} \operatorname{Ir}\left(\mathrm{OH}_{2}\right)_{3}\right]\left[\mathrm{SO}_{3} \mathrm{CF}_{3}\right]_{2}$. Due to the formation of small amounts of catalytically active dimers (see main text). These stuctures are not kinetically competent to be the catalyst generated over the course of the reaction under standard conditions. 

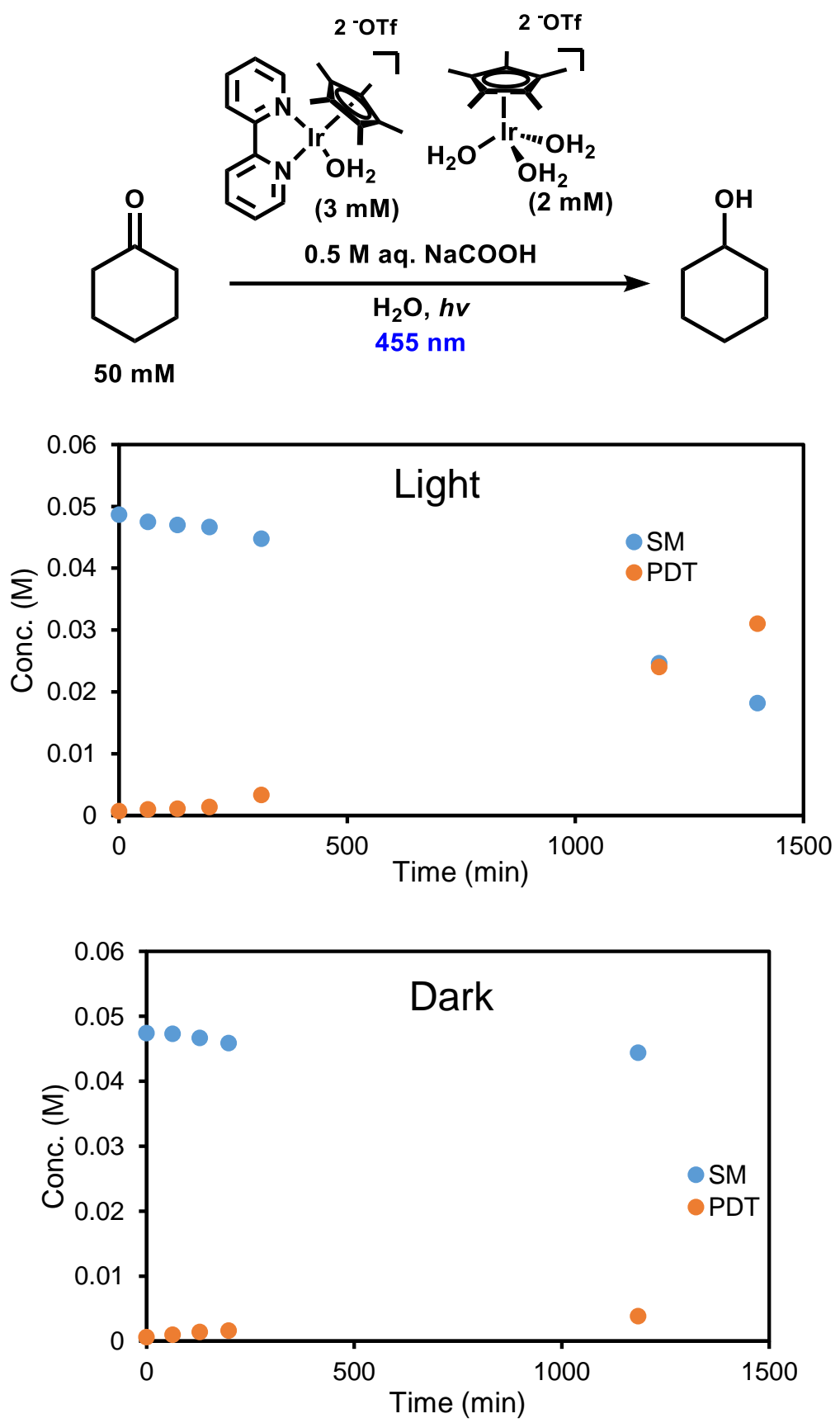

Figure S17. Control experiment with $\left[\mathrm{Cp} * \operatorname{Ir}\left(\mathrm{OH}_{2}\right)_{3}\right]\left[\mathrm{SO}_{3} \mathrm{CF}_{3}\right]_{2}$ and $\left[\mathrm{Cp} * \operatorname{Ir}(\mathrm{bpy})\left(\mathrm{OH}_{2}\right)\right]\left[\mathrm{SO}_{3} \mathrm{CF}_{3}\right]_{2}$ instead of 1-H. The mixture of these species does not enhance the reaction or remove the induction period, suggesting that the photochemical process to generate the active catalyst must be more complicated than simple bpy dissociation. 


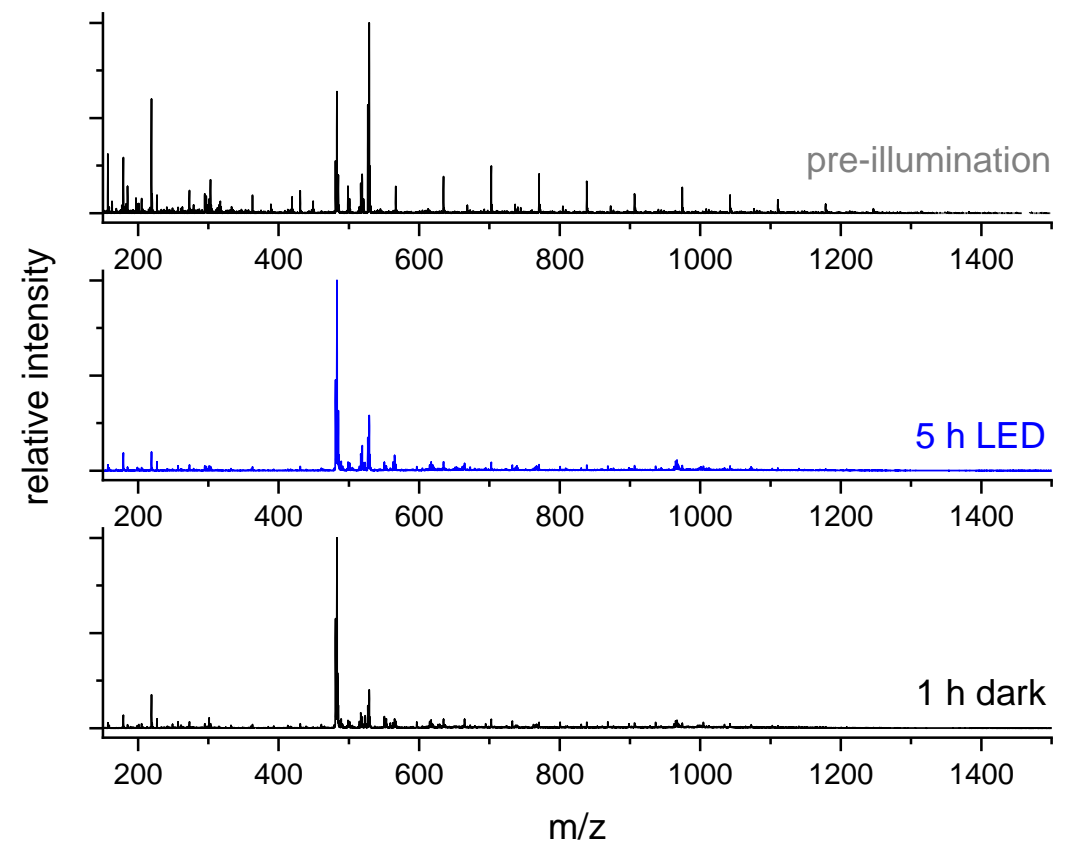

Figure S18. Electrospray ionization mass spectrometry of the reaction mixture before irradiation, after 5 hours of illumination and subsequently after 1 hour in the dark. Signals repeating every 68 mass units are clusters of sodium formate of formula $\left(\mathrm{HCO}_{2} \mathrm{Na}\right)_{x} \mathrm{Na}$.

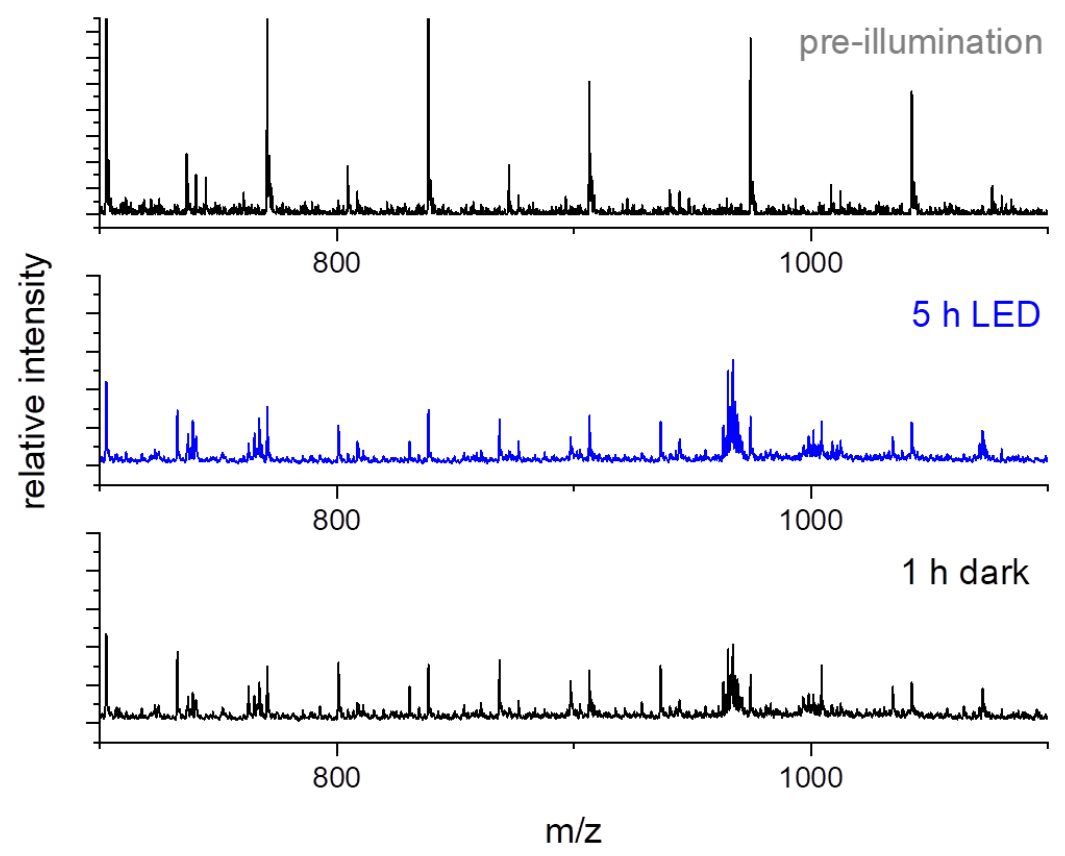

Figure S19. Electrospray ionization mass spectrometry of the reaction mixture before irradiation, after 5 hours of illumination and subsequently after 1 hour in the dark, showing $700-1100 \mathrm{~m} / \mathrm{z}$ showing that multiple higher molecular weight species are generated under reaction conditions. 


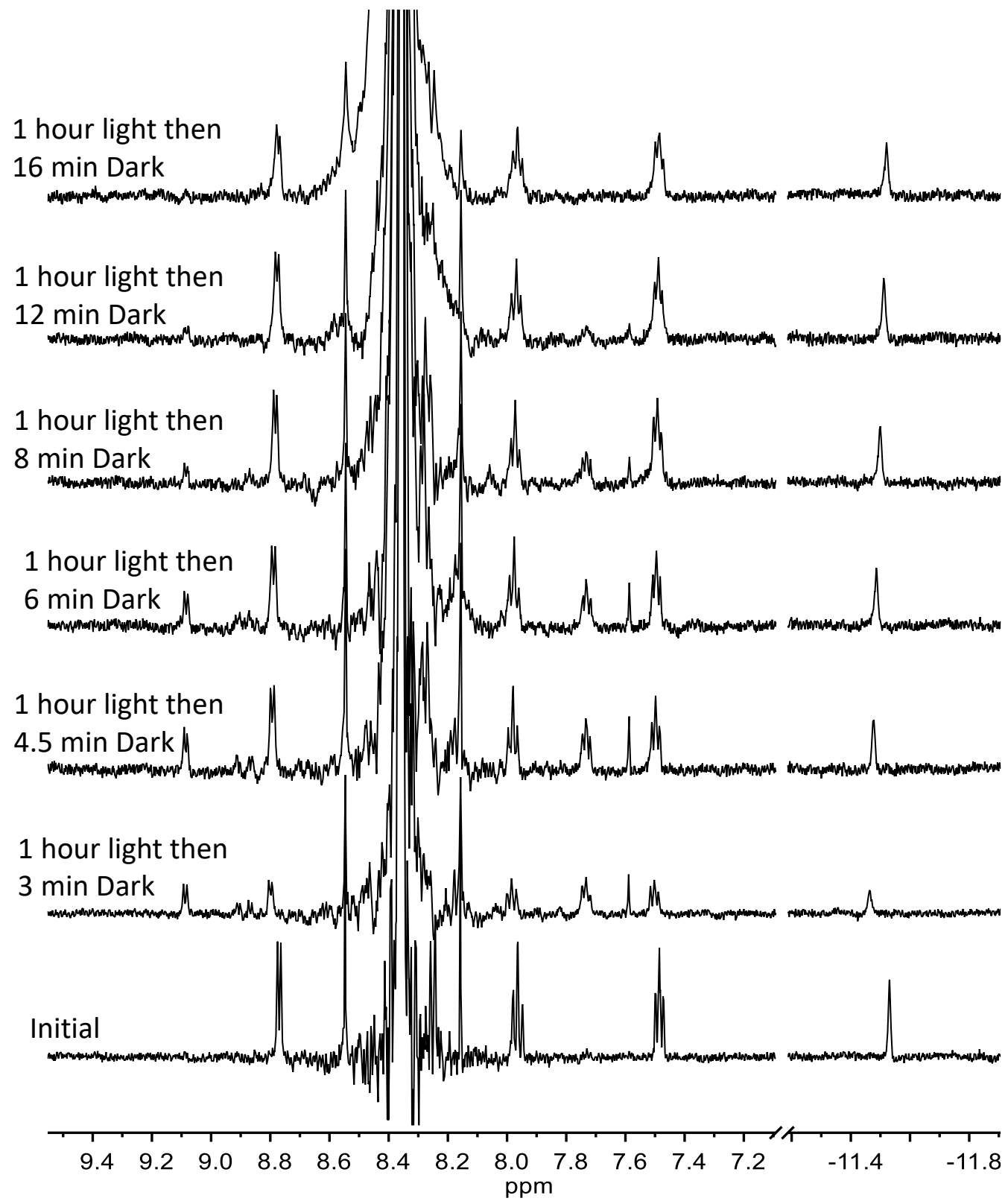

Figure S20. ${ }^{1} \mathrm{H}$ NMR spectra taken shortly after removing the reaction mixture from the light source showing the reformation of the iridium hydride formed from $\mathbf{1 - H}$, which occurs with a half-life of roughly three minutes. 

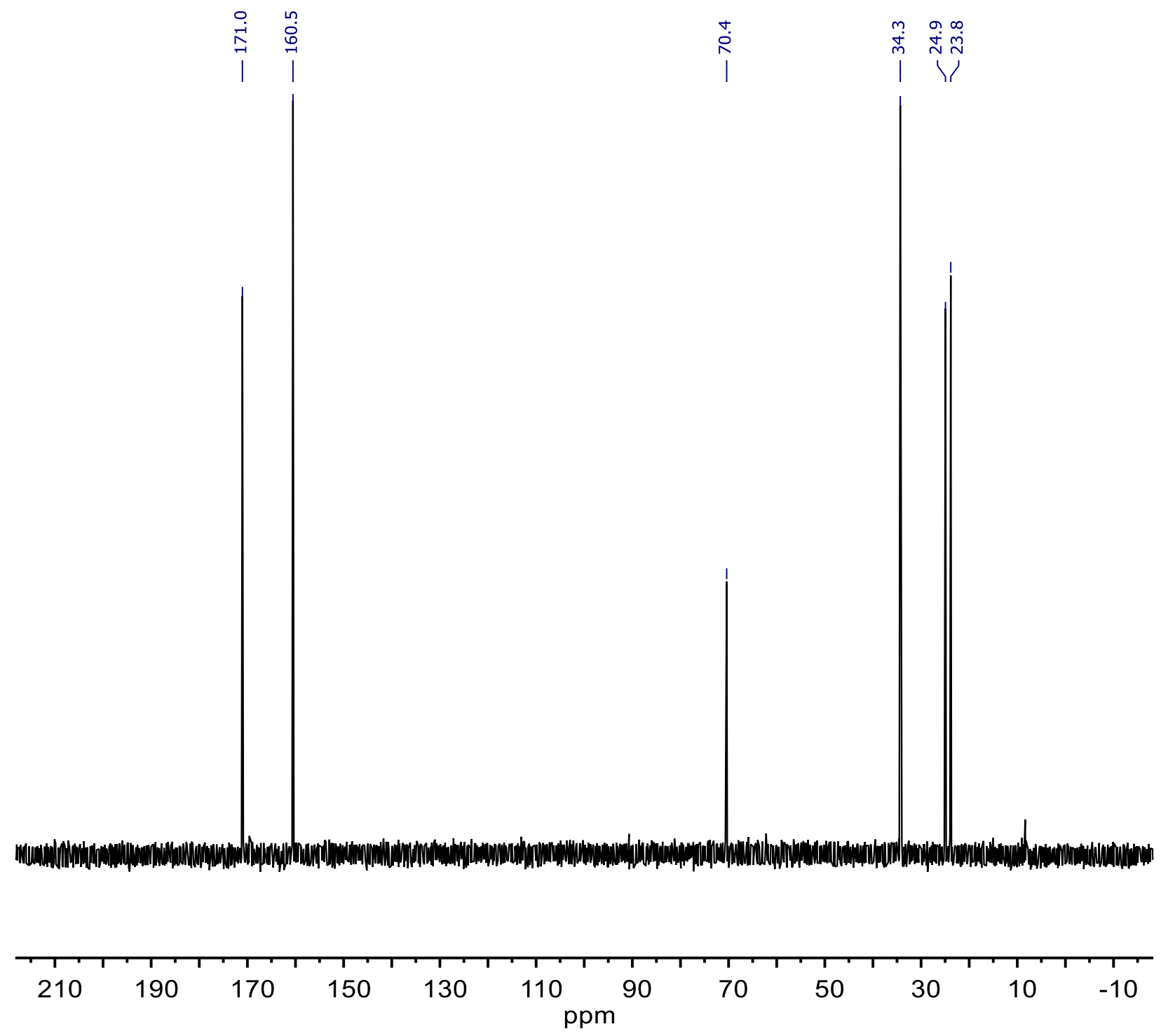

Figure S21. ${ }^{13} \mathrm{C}$ NMR spectrum of cyclohexanone hydrogenation reaction mixture after $20 \mathrm{~h}$ of illumination, with resonances corresponding to formate at $171.0 \mathrm{ppm}$, bicarbonate at $160.5 \mathrm{ppm}$, and cyclohexanol at 70.4, 34.3, 24.9, and $23.8 \mathrm{ppm}$. 


\section{References}

${ }^{1}$ Dadci, L.; Elias, H.; Frey, U.; Hoernig, A.; Koelle, U.; Merbach, A. E.; Paulus, H.; Schneider, J. S. m-Arene Aqua Complexes of Cobalt, Rhodium, Iridium, and Ruthenium: Preparation, Structure, and Kinetics of Water Exchange and Water Substitution. Inorg. Chem. 1995, 34, 306-315.

2 Himeda, Y.; Onozawa-Komatsuzaki, N.; Sugihara, H.; Kasuga, K. Simultaneous Tuning of Activity and Water Solubility of Complex Catalysts by Acid-Base Equilibrium of Ligands for Conversion of Carbon Dioxide. Organometallics 2007, 26, 702-712. ${ }^{3}$ Sasayama, A. F.; Moore, C. E.; Kubiak, C. P. Electronic effects on the catalytic disproportionation of formic acid to methanol by [Cp*|r|rl(R-bpy)Cl]Cl complexes. Dalton Trans. 2016, 45, 2436.

${ }^{4}$ White, C.; Yates, A.; Maitlis, P. M.; Heinekey, D. M. ( $\eta^{5}$-Pentamethylcyclopentadienyl) Rhodium and Iridium Compounds. In Inorganic Syntheses; Grimes, R. N., Ed.; John Wiley \& Sons, Inc.: Hoboken, NJ, 1992; Vol. 29, pp 228-234.

${ }^{5}$ Cayemittes, S.; Poth, T.; Fernandez, M. J.; Lye, P. G.; Becker, M.; Elias, H.; Merbach, $E$. Mechanistic Investigation on the Water Substitution in the $\eta^{5}$-Organometallic Complexes $\mathrm{Cp}^{*} \mathrm{Ir}\left(\mathrm{H}_{2} \mathrm{O}\right)_{3}{ }^{2+}$ and $\mathrm{Cp}^{*} \mathrm{Rh}\left(\mathrm{H}_{2} \mathrm{O}\right)_{3}{ }^{2+}$. Inorg. Chem. 1999, 38, 4309-4316.

${ }^{6}$ S. Ogo, N. Makihara, Y. Kaneko, Y. Watanabe, pH-Dependent Transfer Hydrogenation, Reductive Amination, and Dehalogenation of Water-Soluble Carbonyl Compounds and Alkyl Halides Promoted by Cp*Ir Complexes. Organometallics 2001, 20, 4903-4910.

7 Ji, Y.; DiRocco, D. A.; Hong, C. M.; Wismer, M. K.; Reibarkh, M. Facile Quantum Yield Determination via NMR Actinometry. Org. Lett. 2018, 20, 2156-2159. 